MIDAS

Museus e estudos interdisciplinares

$2 \mid 2013$

Varia

\title{
El Museo Itinerante del Barrio de la Refinería: renovación museológica, memoria popular e identidad vecinal en Rosario (Argentina)
}

The Refinery Neighborhood Mobile Museum: museological renovation, popular memory, and neighborhood identity in Rosario (Argentina)

Horacio Miguel Hernán Zapata, Leonardo C. Simonetta y María Liz Mansilla

\section{OpenEdition}

\section{Journals}

Edición electrónica

URL: http://journals.openedition.org/midas/232

DOI: $10.4000 /$ midas.232

ISSN: 2182-9543

\section{Editor.}

Alice Semedo, Paulo Simões Rodrigues, Pedro Casaleiro, Raquel Henriques da Silva, Ana Carvalho

\section{Referencia electrónica}

Horacio Miguel Hernán Zapata, Leonardo C. Simonetta y María Liz Mansilla, « El Museo Itinerante de Barrio de la Refinería: renovación museológica, memoria popular e identidad vecinal en Rosario (Argentina) », MIDAS [En línea], 2 | 2013, Puesto en línea el 29 abril 2013, consultado el 20 abril 2019. URL : http://journals.openedition.org/midas/232 ; DOI : 10.4000/midas.232

Este documento fue generado automáticamente el 20 abril 2019.

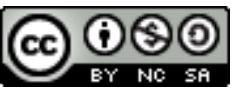

Midas is licensed under a Creative Commons Attribution-NonCommercial-ShareAlike 3.0 International License 


\section{El Museo Itinerante del Barrio de la Refinería: renovación museológica, memoria popular e identidad vecinal en Rosario (Argentina)}

The Refinery Neighborhood Mobile Museum: museological renovation, popular memory, and neighborhood identity in Rosario (Argentina)

Horacio Miguel Hernán Zapata, Leonardo C. Simonetta y María Liz Mansilla

\section{Introducción}

1 El siglo XX culminó con una importante profusión de discusiones en el campo de las ciencias sociales alrededor de la memoria, su presencia en el propio seno de las sociedades contemporáneas y su impacto en las políticas gubernamentales. Dentro de este contexto, los museos han realizado enormes esfuerzos e inversiones para participar de dichas discusiones, modificando sus perfiles institucionales, sus objetivos y generando exposiciones y muestras temporales acordes a los nuevos tiempos y paradigmas vigentes (Castilla 2010; Gutiérrez Usillos 2010). Es sabido que los museos modernos fueron concebidos, al calor del orden burgués del siglo XIX, como espacios de conservación y exhibición del patrimonio simbólico colectivo, como los custodios de aquella cultura material que sostiene los imaginarios nacionales, locales o comunitarios. No obstante, esa función se ha ido complejizando, enriqueciendo y alterando ante la crisis del proyecto de la modernidad.

2 En efecto, a aquellas acciones de conservación y exposición de imágenes, obras y documentos, se ha agregado la necesidad de investigación, documentación y archivo, así como un mayor compromiso con el desarrollo cultural, social y comunitario, y una nueva 
preocupación por la presencia ciudadana (Roigé i Ventura 2010). Ya no se trata de sostener museos obedientes con su papel de formadores de identidad o de continuar planteándolos como lugares donde dejar los grandes legados que deben heredarse a la posteridad, sino de procurar convertir tales instituciones en ámbitos donde la sociedad toda pueda intervenir, polemizar y participar (Arrieta Urtizberea 2008). El espacio del museo es visto, en definitiva, como una arena de debate colectivo sobre la memoria de una sociedad.

3 Además del cuestionamiento hacia un modelo único de museo, con objetivos arquetípicos y funciones ejemplares, el cambio de paradigma significó la oportunidad de ensayar y poner en marcha diversos proyectos museísticos, configurados de modos distintos según sus particularidades y metas. En todo caso, si para algunos el museo continúa desempeñando algún tipo de papel importante en la tarea de conservar y promover la memoria colectiva, es preciso que la institución adquiera cierta flexibilidad para adaptarse a las diversas configuraciones de los imaginarios sociales, buena parte de los cuales se construyen a partir de las prácticas y percepciones de sujetos con identidades móviles y provisionales. De esa manera, el museo será capaz de traducir las identidades existentes a partir de regímenes de identificaciones y posicionamientos variables en políticas museológicas. La representación de las identidades en los museos deja de cimentarse en esencias fijas para pasar a apoyarse en complejos anclajes, en construcciones sociales e históricas más densas que a veces pueden superponerse y/o entrar en conflicto, lo que permite a su vez atender y recrear en la institución los múltiples "nosotros" que existen en la sociedad (la región, la ciudad, el barrio, la religión, la familia, el género, la sexualidad, la etnia) (Hernández Hernández 2003). Por lo tanto, este desplazamiento aporta el margen de maniobra y la agilidad que requiere hoy en día cualquier intento de inscribir un objeto y presentarlo como "patrimonio", así como también abre la posibilidad de imaginar otros modelos museísticos, alternativos al basado en el paradigma clásico occidental y diferentes de la institución que -planificada desde las elites e intelectuales en el poder- funda los mitos de la nación moderna.

En Argentina, la adopción de las premisas de la "nueva museología", aproximadamente desde la década de 1980, permitió que algunos de los primeros museos del país -fundados a fines del siglo XIX- adecuaran sus salas, exhibiciones y prácticas más tradicionales a los requerimientos de los tiempos que corrían. La propia tendencia hizo posible asimismo la organización y gestión de nuevas instituciones y experiencias museológicas. A la fecha, podemos aseverar que tanto los museos de vieja data como los de reciente creación han generado un abanico de propuestas de exhibiciones y actividades en las que resuenan, con diferentes intensidades, los nuevos paradigmas museológicos, buscando además renovar las formas de comunicación e interacción con el público. La toma de conciencia de estas condiciones y circunstancias ha hecho necesaria la búsqueda por encontrar estrategias de organización y gestión museológica acordes a las políticas culturales y programas históricos o didácticos de nuestra época y que hagan actuar a los museos como instituciones capaces de traducir la pluralidad de situaciones y características políticas, sociales y culturales del país, sin renegar de asumir también las asimetrías y fracturas presentes en la sociedad argentina.

5 Para analizar la forma en que se tradujeron tales discursos y políticas museológicas en la ciudad de Rosario, el presente artículo expone algunas de las condiciones y supuestos bajo los cuales un museo en particular, el Museo Itinerante del Barrio de la Refinería, configura una propuesta específica de exhibición y lectura del patrimonio. Nos 
detendremos en aquellas características sobresalientes que definen la trayectoria de este museo hasta el día de hoy y que pueden resumirse básicamente en dos variables: en primer lugar, el emplazamiento físico particular en el que acota su espacio de trabajo. Tal como se desprende del propio nombre institucional, el museo restringe su radio de acción al Barrio de la Refinería, una de las divisiones de infraestructura urbana que se constituyó al calor de los procesos socioeconómicos que vivió la ciudad de Rosario desde fines del siglo XIX y principios del XX. Y en segundo lugar, el protagonismo otorgado a ciertos grupos sociales no incluidos habitualmente en los discursos oficiales de la memoria histórica de Rosario (Simonetta y Zapata 2011). A diferencia de otros museos locales, como el Museo Municipal de Bellas Artes "Juan B. Castagnino", el Museo Histórico Provincial "Dr. Julio Marc" o el Museo Municipal de Arte Decorativo "Firma y Odilo Estévez", emparentados éstos con los imaginarios burgueses de principios del siglo XX y las expresiones legitimadas de la historia nacional y regional (Esquivel, Simonetta y Zapata 2008a; 2008b; Simonetta y Zapata 2010; Zapata y Simonetta 2011; 2012; Zapata, Simonetta y Esquivel 2010; Zapata, Simonetta y Mansilla 2011; 2012), el Museo Itinerante del Barrio de la Refinería centra su atención en las memorias de aquellos actores subalternos de la trama local y que aquí definiremos como sectores populares urbanos ${ }^{1}$.

6 Tener en mente ambos aspectos nos permitirá finalmente reflexionar sobre algunas de las coordenadas de las muestras permanentes y temporales llevadas a cabo en los últimos años por el Museo Itinerante del Barrio de la Refinería, y ponerlas en directa relación con las exigencias de memoria y respeto a la diversidad sociocultural que han venido consolidándose dentro de la sociedad argentina.

\section{Revisitando el Barrio Refinería de Rosario}

7 En tanto la organización y dinámica de las actividades y muestras que se proponen desde la gestión del museo estudiado aquí resultan indisolublemente unidas a un emplazamiento físico particular, creemos necesario, como primer punto de análisis, ubicar la configuración del Barrio Refinería, el espacio que cobija en la actualidad al museo.

Desde mediados del siglo XIX, Rosario pasó de ser una pequeña villa a convertirse en una ciudad activa y cambiante gracias al aprovechamiento de las ventajas económicas que traía aparejada su ubicación privilegiada en el Litoral. En efecto, su localización estratégica no sólo le asignaba un papel de puerto "natural" para el intercambio interno y externo en el marco del creciente afianzamiento del modelo agroexportador -esto es, para la salida de los cereales provenientes de las colonias agrícolas de las provincias de Santa Fe y Córdoba y la entrada de manufacturas extranjeras - , sino que además la convertía en un punto de convergencia de las rutas terrestres y vías de ferrocarriles que comunicaban al Litoral con Buenos Aires, con las provincias del interior y con el resto de la región pampeana. Rosario se transformó rápidamente en una urbe moderna y cosmopolita ocasionado tanto por el marcado incremento de su población como por la consecuente modificación de su casco urbano que debió adaptarse a las cambiantes condiciones impuestas por las actividades comerciales, financieras, manufactureras e industriales (Videla y Fernández 2000).

9 Con el puerto y el ferrocarril, los negocios inmobiliarios aparecían como otro campo de inversión sumamente atractivo. Los progresivos cambios en el trazado de la ciudad y la realización de nuevas obras fueron generando un espacio rentable para la inversión de 
capitales, a lo que se agregaba la entrada en el juego especulativo de compra-venta de tierras en la periferia o en la campaña circundante. Para algunos actores, particularmente para los miembros de la burguesía local, la propiedad de la tierra supuso rentabilidad y posibilidades de acumulación, mientras que para las clases medias significó una modalidad de asentamiento definitivo en determinadas zonas del locus urbano. Además, la consolidación de un mercado inmobiliario no sólo posibilitaba generar nuevas formas de infraestructura urbana sino, especialmente, asegurar una paulatina diferenciación, tanto en términos espaciales como sociales.

Pero más allá de esta caracterización del espacio urbano de Rosario y su proceso de redefinición, es necesario advertir que la zona norte de la ciudad tuvo en sí misma un desarrollo particular. Incentivados por la proximidad del río, por la llegada del ferrocarril y por los costos relativamente bajos de la tierra en el área, un número significativo de empresarios optó por adquirir terrenos en la zona con el fin de desarrollar allí diversas actividades productivas ligadas a la agroexportación. Entre 1885 y 1895, la oferta de tierras en la zona aumentó, al tiempo que los "suburbios del norte" se iban poblando de fábricas, talleres, barracas de "frutos del país" y embarcaderos que, en la medida en que demandaban un creciente número de trabajadores, fueron generando el asentamiento de los mismos en las cercanías (Lanciotti 2009). Sin embargo, más allá de la miríada de nuevos establecimientos que iban surgiendo, dos de ellos destacaron por sobre los demás: los Talleres del Central Argentino y la Refinería Argentina del Azúcar (Prieto 1991).

11 Desde la década de 1870, la industria azucarera argentina se asentó en una combinación de políticas proteccionistas y mejoras tecnológicas que le permitieran superar una serie de dificultades. Las tierras productoras de materia prima se hallaban concentradas en las provincias del norte (especialmente en Tucumán, Salta, Jujuy, Chaco y Formosa), por lo que la comunicación de éstas con los distantes centros de consumo del litoral era un escollo insoslayable que requería de soluciones prontas y de largo plazo, situación que tendió a modificarse con la llegada del ferrocarril en 1876, uniendo a Tucumán, Córdoba y el puerto rosarino (Guy 1988, 356).

En 1886 se puso en marcha la construcción de la Refinería en un terreno al norte de la ciudad. La fábrica daba trabajo a una importante cantidad de obreros encargados de desarrollar una determinada tarea dentro de la organización interna de la producción de la empresa, a los que se sumaban otros agentes, como los capataces, oficiales y aprendices. Los obreros podían ser varones, mujeres, e incluso niños, muchos de los cuales eran inmigrantes provenientes de Europa (Prieto 1991, 109). Su asentamiento en torno a los lugares de trabajo y producción fue configurando la aparición de barrios que tomaban el nombre de los establecimientos que les habían dado vida, entre ellos, "Embarcaderos", “Aguas Corrientes", “Talleres", "Graneros", "Molinos" o "Refinería”. (Prieto 1991, 110).

Desde el punto de vista urbanístico, y muchos por años, los "barrios del norte" entablaron una relación singular con el centro de la ciudad, signada por el aislamiento. A las complicaciones por la escasa e ineficiente comunicación con el resto de la ciudad se sumaban las precarias condiciones de infraestructura y de sanidad de las viviendas. Según Prieto (1989-1990), las viviendas abarcaban un amplio espectro de tipologías, siendo las más comunes en estos barrios el rancho de paja y barro, la casilla de madera o lata y el conventillo. Si las dos primeras eran ocupadas preferentemente por los trabajadores temporarios de las fábricas, el conventillo era la opción habitacional a la que solían apelar 
los trabajadores estables de las empresas, aunque excluyendo a la "elite obrera" de las mismas, para la que se habían hecho construir casas.

Los debates en torno a la importancia del trazado urbano y a la elaboración de planificaciones acordes a los cambios que iba atravesando la ciudad motivaron la confección de planes que ahondaban en estas problemáticas desde diversas perspectivas. En particular, desde la década de 1930, el tema cobró nueva fuerza en tanto se avizoraban nuevos cambios en la composición y en el ordenamiento de la urbe, que se enmarcaban en el contexto de mutaciones más generales que comenzaba a atravesar la Argentina.

Por otro lado, se operaron y acentuaron características novedosas en el trazado y expansión de la ciudad. El centro amplió su área de influencia y concentró aún más actividades vinculadas a servicios y a la administración gubernamental. La periferia, por su parte, tendió a ser concebida en relación a sus funciones residenciales e industriales. Los nuevos loteos de tierras en barrios caracterizados por contar con cárceles, cementerios u hospitales permitieron una cierta ampliación de la población asentada en los mismos. Paulatinamente se iba gestando una imagen nueva del barrio o del suburbio, asociado ahora al rosarino medio y a la instalación de bibliotecas populares, vecinales, clubes y centros de distinto tipo.

Al calor de los cambios en la fisonomía de los barrios, se delineaban también nuevas identidades y espacios de sociabilidad que las contenían y reforzaban; en particular, las asociaciones vecinales. Tal como indican Agnese et al. (1997), desde fines del siglo XIX y hasta la década de 1920, el surgimiento de las comisiones vecinales fue alentado tanto por incentivo de un gobierno municipal interesado en controlar a distintos sectores de la ciudad asegurando en ellos su jurisdicción y cierta presencia, como por el accionar y la voluntad directa de propietarios de tierras más o menos alejadas del centro, bajo la certeza de que las obras que estas comisiones lograrían obtener del poder municipal revalorizarían más los terrenos de la zona. En adelante, estas entidades lograrían ampliar sus posibilidades de acción, adoptarían la nomenclatura de vecinales y aparecerían como agrupaciones realmente animadas por los vecinos, aunque manteniendo una de sus funciones originales y más importantes al arrogarse la tarea de peticionar ante el poder municipal la satisfacción de sus demandas, centrando sus reclamos en torno a las obras de salubridad, agua corriente, cloacas, suministro de energía eléctrica, adoquinado, parquización de espacios libres o plantación de árboles en las veredas (Roldán 2006, 81-88; 2010).

Por varios años, el barrio Refinería asistió y participó activamente en las modificaciones económicas, sociales, culturales y políticas que fueron dejando su impronta en la ciudad. Desde sus orígenes en torno a la Refinería del Azúcar hasta la actualidad, sus pobladores han ido delineando -y a su vez resignificando- una identidad barrial plasmada en la imagen del vecino y sus asociaciones, escuelas, clubes y bibliotecas públicas (Nicoletti, 1998). Con el transcurrir del tiempo, la impronta de la refinería y la plasmación de un imaginario del barrio como netamente obrero se fue complejizando en la medida en que daba cabida a nuevas formas de autopensarse y concebirse. En este sentido, la aparición del Museo Itinerante del Barrio Refinería actúa -aunque no siempre conscientementecomo un receptor de objetos y memorias que permiten reconstruir percepciones y sentires, identidades y prácticas de un conjunto de varones y mujeres a lo largo del siglo $\mathrm{XX}$. 


\section{Un museo para el Barrio}

18 En 1999, se ponía en marcha la creación del Museo Itinerante del Barrio de la Refinería a partir de la donación inicial de un vecino del barrio Islas Malvinas (ex Refinería), la cual reunía una cantidad importante de objetos donde se mezclaban juguetes y fotografías que cubrían un amplio arco temporal y que, excediendo la memoria de una familia en particular, remitía al acontecer cotidiano en la vida de los pobladores del barrio durante buena parte de su existencia.

19 A partir de este corpus inicial se organizaron las primeras exposiciones y se decidió dar un cariz singular a esta apuesta museológica apelando a la itinerancia de las muestras. La conformación de un circuito más o menos delimitado operó como un elemento fundamental para el establecimiento de relaciones institucionales y para generar una plataforma adecuada a partir de la cual dar a conocer el museo y su contenido, así como acercar a la población del barrio al museo y a las muestras propuestas desde el mismo. Este planteo intentaba dar respuesta a las dificultades que se iban generando, en especial, la cuestión del espacio físico y la falta de un flujo de recursos económicos constantes.

Con los años, el Museo Itinerante del Barrio de la Refinería ha visto incrementarse sus colecciones y su capital humano. De esta manera, se pudieron planificar las numerosas exposiciones realizadas hasta el momento, establecer vínculos con la Municipalidad y con otras instituciones públicas de la ciudad donde llevar adelante actividades, coordinar encuentros de historiadores barriales o poner en funcionamiento los mecanismos más convenientes para la difusión del quehacer del museo, entre los que se encuentran la creación y actualización permanente de un blog propio en Internet (http:// museorefineria.blogspot.com/) que es complementado con el envío a direcciones de emails particulares de boletines informativos que toman como centro historias, objetos o anécdotas que tienen que ver con el acontecer del barrio.

21 La apuesta versa en tomar a los museos como espejos que intepelan a la sociedad, a la vez que se concibe al objeto no como un mero producto sólo digno de admiración y veneración sino como una pieza clave de reflexión y de conocimiento sobre la sociedad. No se trata de dar a los visitantes respuestas fáciles y orientadas sino de proponerles y acercarles el desafío de sacar conclusiones propias a preguntas sobre el presente disparadas por lo expuesto en el museo. En esta labor colectiva, donde interactúan los visitantes y los especialistas, el objeto puede movilizar preguntas sobre el pasado y, al mismo tiempo, sobre la propia situación del barrio y sus pobladores en la actualidad:

No es objetivo, entonces, saber más sobre la inmigración o los dinosaurios, sino sobre las huellas que los inmigrantes dejaron en nuestra sociedad, o porqué los dinosaurios ejercen tal o cual impresión sobre nosotros. Con esta perspectiva, los innumerables objetos de los museos son piezas inestimables para el conocimiento de la sociedad actual, a través de lo que otras sociedades dejaron. No es que no importe saber sobre otras sociedades, culturas o épocas. Sí importa, pero no es lo único (MIBR* 2008a; 2008b).

Estas ideas y postulados pueden verse plasmadas de distinto modo en el accionar del museo. En particular, nos interesa centrarnos en dos experiencias fundamentales: las exposiciones itinerantes y las Jornadas de Historiadores Barriales.

Las muestras y exposiciones del Museo Itinerante del Barrio de la Refinería han sido muy numerosas y de temáticas diversas, aunque siempre han tenido como hilo conector su 
vinculación con el barrio y/o con la historia de la ciudad. La primera de ellas se organizó al poco tiempo de haber tendido las bases a la organización de la entidad y adoptó una lógica que la dividía en grandes temáticas afines al pasado de la zona. Así, entre 1999 y 2002, la muestra Refinería -que comprendía los tópicos de "vida cotidiana, conventillo, huelga"- hacía su aparición en la Escuela Nacional de Comercio General Las Heras para recorrer un circuito que anclaba en varias instituciones del barrio donde los vecinos de distintas edades pudieran acercarse las veces que creyeran conveniente. Las escuelas del barrio fueron escenarios privilegiados para el montaje de las muestras, pero no fueron los únicos. También se recurrió, en reiteradas oportunidades, al Centro Municipal de distrito Zona Norte Villa Hortensia, al Centro Cultural Fisherton, al Centro Cultural Cine Lumière o al Ente de Turismo Rosario, entre otros. Las fotografías, revistas, monedas, soldados de plomo, plástico y metal, juguetes o tarjetas postales permitieron echar luz sobre fragmentos del pasado pensados el términos de historias-problema críticas que apuntaban al conocimiento y estudio de los hombres y mujeres "anónimos" del barrio. Los objetos se transforman en observatorios desde donde comprender un proceso histórico a partir de la dialéctica preguntas-respuestas que se establece desde la muestra y desde la interpelación y apropiación de los mensajes vehiculizados a través de los objetos y las exposiciones. Ejemplos de ello fueron las muestras "Rituales" (1999), "Soldaditos" (2000-2001), "El Rosario Colonial” (2001) y "Caras y Caretas (cien años después)” (2002), donde se buscaba incentivar una visión crítica del lugar de la mujer, la política, el juego, la guerra, los orígenes de la ciudad o el amor apelando a fotografías, soldaditos de plomo, plástico y metal objetos coloniales y revistas respectivamente, pero teniendo en cuenta contextos históricos mayores donde esos objetos y sus mensajes cobraban significado.

Si bien la apuesta es acercarse a la vida del barrio, al reconocimiento de sus actores sociales, a los imaginarios colectivos y al perfil edilicio -hoy fuertemente afectado por las modificaciones y destrucciones en pos de la "modernización"- el Museo Itinerante del Barrio de la Refinería no buscó -ni busca en la actualidad- arrogarse el papel de creador de una única memoria del barrio, ni ser el encargado de rescatar y resguardar una identidad que tiende a perderse al compás de los cambios en el paisaje urbano. En todo caso, afirma Fernetti, "no somos la memoria del barrio sino el lugar de confianza donde poner los objetos" (2010), se trata de facilitar las herramientas con las que los visitantes puedan compartir sus conocimientos, ampliarlos y, desde esa base, crear los elementos para reconocerse como parte de un grupo colectivo mayor. Las muestras son una de ellas, donde un público de edades diferentes puede detenerse a observar y reflexionar en función de una o varias ideas que giran en torno a la selección de objetos y al guión pensado para cada ocasión. A estas se agregan otras experiencias muy importantes para los impulsores del museo así como para quienes se consideran los depositarios del conocimiento sobre el pasado del barrio.

26 A partir de 2002, los miembros del Museo Itinerante del Barrio de la Refinería comenzaron a ponderar la posibilidad de ampliar el abanico de actividades desarrolladas desde la institución. Así se iniciaron los Ciclos, bajo temáticas y objetivos diferentes. Ese mismo año se organizó el Ciclo permanente de encuentros de historiadores barriales y el Encuentro de artistas y artesanos del barrio Refinería. Este último tenía como horizonte crear un lazo entre los vecinos y generar un espacio de encuentro propicio para que se expusieran actividades u objetos desarrollados por los mismos. Así, a las fotografías se unieron pinturas, artesanías, telar, baile, canto, actuaciones de teatro y poesía (MIBR 
2006). Esta motivación subjetiva e individual, no sólo en el estilo de pintura sino también en la temática, tiene mucho que ver, en última instancia, con una identidad propia que los pobladores de Refinería han ido construyendo con el correr de los años y que remite a espacios conocidos ("el río") o a los afectos ("la nieta"): "Tener un museo barrial implica adoptar las costumbres del barrio, no es la del centro trasladad acá. La idea es que lo mismo del barrio dispare otras cosas" (Fernetti 2010).

Aunque el Museo Itinerante del Barrio de la Refinería comparte funciones con otros museos -especialmente si nos atenemos a las reseñadas anteriormente -, existen otros elementos que le otorgan una particularidad. Justamente, el Ciclo permanente de encuentros de historiadores barriales deviene en una plataforma desde la cual el museo puede proyectarse hacia la sociedad y hacer un ejercicio de devolución a la misma. Con una frecuencia bimestral, los Encuentros de Historiadores Barriales en el Centro Cultural Cine Lumière buscan "homenajear, rescatar y colaborar con los recopiladores, historiadores, aficionados a la historia y amigos de los barrios de Rosario a través de documentos elaborados por los mismos" (MIBR 2008c). De esta manera se trata de propiciar el encuentro entre vecinos de distintos barrios que se han dado a la tarea de recopilar anécdotas, historias y todo tipo de materiales - fotografías, material periodístico - (MIBR 2007), creando un ámbito de camaradería y amistad donde se pueden discutir temas históricos atinentes a los barrios de la ciudad. En estas experiencias de comunicación intergeneracional e intercultural, cada uno aporta modos de pensar, sentir y actuar distintos, que están plasmados en las formas de la convivencia que se tejen día a día. Así, no sólo se complementan las investigaciones particulares con nuevos datos, sino que se cumple con otro de los objetivos del museo: ayudar a mejorar la calidad de vida en la medida en que las personas encuentran un espacio donde escuchar y ser escuchados, una experiencia a partir de la cual se concibe que "contar la historia colectiva es saludable" (MIBR 2008c). Se trata, en última instancia, de devolver el derecho de contener las memorias, un derecho que el propio museo se arroga cuando monopoliza y se da a la tarea de administrar los objetos y los mensajes que se generan a partir de ellos (MIBR 2009).

Desde 2006, los encuentros de historiadores barriales se complementaron con las Jornadas de Historiadores y Cronistas Barriales, realizadas anualmente y convocadas a nivel nacional. Estas jornadas, que ya cuentan con cuatro eventos en su haber, giran en torno a grandes temas que van cambiando año a año. Así, a la temática "El barrio" le siguieron "El juego" (2007), "El Ferrocarril" (2008) y "Cine barrial y popular" (2009), contando con la asistencia de historiadores de Buenos Aires, Córdoba, Entre Ríos y Rosario. Los objetivos de las mismas se orientan hacia el rescate de documentos importantes en distintos soportes para darlos a conocer y realizar investigaciones; acercarse a la memoria de la comunidad no sólo a través de los documentos sino también ponderando el recuerdo y la transmisión oral; promover la participación de la ciudadanía, con especial énfasis en los jóvenes; interesar a la comunidad educativa de cada barrio en la participación y difusión de los trabajos presentados; agrupar a investigadores y cronistas dedicados al estudio de la historia barrial y llegar a la construcción de un espacio horizontal donde se generen vínculos que trasciendan a las instituciones y motoricen la divulgación de los trabajos (MIBR 2008d).

Las actividades que desarrolló desde su fundación el Museo Itinerante del Barrio de la Refinería, como también las propias políticas implementadas en los últimos años variaron conforme a las necesidades y circunstancias. Sin embargo, en todas ellas sobresale la 
constante búsqueda por involucrar directamente a la comunidad local que abriga al museo. Podemos afirmar entonces que la principal característica que define la mayoría de las iniciativas llevadas a cabo desde el Museo Itinerante del Barrio de la Refinería es su orientación comunitaria y local, puesto que se trata de proyectos compartidos por quienes sienten que es necesario un trabajo de reconstrucción de la memoria popular y de la cultura barrial. De esa manera, la estrecha relación entablada con la comunidad de vecinos del barrio, atendiendo a sus saberes, motivaciones, intereses y experiencias personales, ha sido la marca más significativa de la forma en que tal institución construye sus funciones museológicas.

No obstante, es necesario remarcar que estos cambios obedecen a políticas culturales que superan los procesos que tienen lugar en el ex Barrio Refinería de la ciudad de Rosario, para inscribirse en fenómenos de alcance global, como el cuestionamiento de una memoria identificada con el Estado, los procesos de globalización, la movilidad de las fronteras culturas, entre muchos otros factores, que han desplazado el eje de atención de las políticas de valoración y preservación patrimonial hacia diversos ámbitos del mundo actual, más concretos y cercanos a los grupos y experiencias de las sociedades contemporáneas. En efecto, las prácticas de este museo barrial de la ciudad de Rosario es apenas un ejemplo de cómo las demandas e iniciativas de regiones, localidades y particulares en materia de memoria y patrimonio han crecido en los últimos años. Es justamente esta perspectiva la que procuramos ampliar y poner en juego en las reflexiones que siguen a continuación y que cierran nuestro trabajo.

\section{A modo de cierre}

31 La historia social de los museos es un ámbito interdisciplinario que puede aportar elementos para la comprensión de las políticas, concepciones y prácticas desarrolladas desde su creación y puesta en funcionamiento. Este ámbito incluye también la posibilidad de revisar cómo se construyeron las formas de organizar y exhibir las colecciones, de qué manera se elaboran las políticas que se llevan a cabo en los museos en la actualidad y cómo se traducen e incorporan las nuevas ideas, convenciones y paradigmas que circulan en los campos de la museología, la historia, la antropología, la sociología, etc. Las actuales tendencias nos muestran que, a partir de estudios puntuales, es posible detenerse sobre el perfil de cada museo y preguntarse insistentemente acerca de los objetivos persigue, a través de qué proyectos busca cumplir sus metas, cuál es la relación que establece con la sociedad civil, a través de qué canales procura interactuar con sus públicos más cercanos, qué dificultades encuentra para hacerlo.

Realizar esta serie de interrogantes a la historia de estas instituciones en Argentina no parece entonces un ejercicio vano, puesto que en los últimos años muchos de los museos del país han cambiado sus rostros y han institucionalizado nuevas y renovadas formas museológicas de definición y acción. La mayoría de estos han generado estrategias, muestras, recorridos y actividades diversas, adecuados a las necesidades e intereses concretos de cada sociedad, en las que el público visitante deja de ser ese ente distante (que observa y contempla de forma pasiva) para convertirse en un sujeto que participa activamente (a través del diálogo, el intercambio y la construcción conjunta de conocimiento). En este camino, cada uno de los museos argentinos recibió el influjo de las polémicas sostenidas en varios países (Morales Moreno 2000; Díaz Balerdi 2002; Castilla 2010), consistentes en prestar mayor atención pública a los objetos, los usos, las 
costumbres, las idiosincrasias y los saberes cotidianos de la sociedad contemporánea e incorporarlos como nuevos contenidos de significación patrimonial. Ahora bien, no todos participaron con la misma intensidad y ritmo de los cambios que traía aparejado el debate sobre los sentidos del patrimonio, la memoria y la democratización de los espacios expositivos. Cada uno hizo lo propio en el contexto de un mundo diverso, desigual y fragmentado en términos sociales, políticos y económicos, pero ciertamente lo hicieron poniendo en diálogo temáticas globales con contextos nacionales y regionales.

En este sentido, la historia del Museo Itinerante del Barrio de la Refinería nos permitió observar, por una parte, el carácter local que asumieron los nuevos modos de entender al museo, sus objetivos y funciones; pero por otra parte, este estudio específico nos posibilitó asumir que dicho episodio en la historia de los museos y sus exposiciones en la ciudad de Rosario no debe interpretarse como un proceso aislado o incidental, sino como parte de una experiencia más amplia. En una mirada más atenta a este juego de escalas y renovación de ideas, podemos subrayar dos líneas de reflexión.

Una primera línea, que se percibe con la inmediatez del caso concreto analizado aquí, nos autoriza a decir que la historia del Museo Itinerante del Barrio de la Refinería se halla íntimamente conectada al mundo del barrio análogo, cuyos habitantes se perciben como portadores de una misma filiación social, anclada en elementos comunes e históricamente construidos. El carácter cambiante del proceso identitario ha permitido que, por razones históricas y culturales específicas, este barrio se diferencie respecto de los otros sectores urbanos de la ciudad. La construcción histórica del barrio como un espacio "propio" influye en la delineación y percepción del patrimonio del museo. El patrimonio es interpretado también como algo "propio" en los términos de una "comunidad" de personas que comparten códigos y costumbres socialmente significativos. La institución museo se asume como un espacio depositario y custodio de un patrimonio que le ha sido "confiado" por las diferentes generaciones que habitaron el barrio. Un legado patrimonial en torno al cual se forja una identidad colectiva y que a la vez configura ciertos rostros de la cultura vecinal. Sus actividades han contribuido a despertar la conciencia de varios grupos (sociales, etarios, sexuales) del barrio acerca de la realidad de su patrimonio cultural, es decir, aquellos bienes simbólicos y materiales que han hecho suyos a lo largo de la historia y que de alguna manera los caracteriza como colectividad vecinal, y en relación con los otros, los diferencia. En una escala local, observamos entonces que la trayectoria del Museo Itinerante del Barrio de la Refinería evoca un conjunto de rasgos identitarios que se configuran en el interior de un contexto y que una comunidad considera fundamentales para su definición social, caracteres que luego son apropiados y resignificados en el texto museográfico.

Y una segunda línea de reflexión, de más largo alcance, nos señala que la trayectoria del Museo Itinerante del Barrio de la Refinería también marcha al compás de estas luchas globales por el respeto a la pluralidad sociocultural y a la participación de la sociedad en la concepción y operación de los nuevos museos que se crean como espacios representativos de esas visiones, identidades e intereses heterogéneos. Y esto ocurre porque su accionar está menos asociado a la idea de dar cabida a identidades vinculadas con la nación o la provincia que a la postura de incentivar la plasmación de las configuraciones identitarias más próximas y concretas. Esta institución busca no sólo cumplir con las funciones clásicas de conservación, investigación y difusión del patrimonio que debe realizar todo museo, sino también propiciar la participación de los vecinos en todas las actividades del mismo, desde la producción semiótica-discursiva del 
texto museográfico hasta la recepción de la información. El espíritu colectivo está dirigido a resistir el olvido de lo propio, convirtiéndose así en el museo de grupos sociales que tratan de reconstruirse y perdurar en el tiempo, independientemente de las intervenciones de sujetos que bajo la forma de asesorías museológicas determinan el sentido museográfico de las exposiciones. En las muestras de exposición, la comunidad reinterpreta su pasado y su presente conforme a los objetos exhibidos, se reconoce y refuerza cada etapa como colectivo con una tradición patrimonial y una identidad social compartida. Desde una perspectiva global, el Museo Itinerante del Barrio de la Refinería participa, por consiguiente, en las tareas de preservar y exhibir la cultura del espacio social y material al que pertenece, los bienes materiales de la gente que lo habita. Así como también busca transmitir las formas de pensamiento, costumbres y el universo cotidiano de los ciudadanos de un ámbito que les es propio: el barrio.

\section{BIBLIOGRAFÍA}

Agnese, Graciela, Liliana Brezzo y Mónica Martínez. 1997. Rosario y sus vecinales. Movimiento histórico y perspectivas. Rosario: Dirección General de Vecinales/ Municipalidad de Rosario/ Editorial La Gráfica.

Arrieta Urtizberea, Iñaki. 2008. Participación ciudadana, patrimonio cultura y museos. Entre la teoría y la praxis. Bilbao: Servicio editorial de la Universidad del País Vasco.

Barrera, Marco. 1993. "Pueblos, espejos y reflejos”. In Tercer Curso Interamericano de Capacitación Museográfica. Antología, 116-122. México: Escuela Nacional de Conservación, Restauración y Museografía "Manuel del castillo Negrete", INAH.

Bonaudo, Marta S. comp. 2006. La organización productiva y política del territorio provincial (1853-1912) . Tomo VI. Rosario: Editorial Prohistoria/La Capital.

Bonaudo, Marta, Élida Sonzogni, Silvia Cragnolino y María Elena Albaizeta. 1993. "Ferrocarriles y mercado de tierras en el centro-sur de Santa Fe (1870-1900)”. Siglo XIX. Revista de Historia 6:37-64.

Castilla, Américo. 2010. "La memoria como construcción política”. In El museo en escena. Política y cultura en América Latina, comp. A. Castilla. 15-36. Buenos Aires: Paidós.

Díaz Balerdi, Ignacio. 2002. “Qué fue de la nueva museología? El caso de Québec”. Artigrama. Revista del Departamento de Historia del Arte de la Universidad de Zaragoza 17:493-516.

Esquivel, Misael, Leonardo Simonetta y Horacio Miguel Hernán Zapata. 2008a. “De casa burguesa a casa-museo. La construcción de la memoria pública de una familia rosarina: el caso del Museo Municipal de Arte Decorativo 'Firma y Odilo Estévez' de Rosario”. In Actas del 3.ํㅡㄹcuentro "La Problemática del Viaje y los Viajeros”. América Latina y sus miradas. Imágenes, representaciones e identidades (Tandil, 14, 15 y 16 de agosto de 2008) [CD-ROM]. Tandil: CESAL-ISHIR/CONICET y Escuela de Historia - UNR.

Esquivel, Misael, Leonardo Simonetta y Horacio Miguel Hernán Zapata. 2008b. "El porvenir de una colección. Imaginarios y representaciones de una familia burguesa: el caso del Museo Municipal de Arte Decorativo ‘Firma y Odilo Estévez' de Rosario”. In Actas de las Jornadas de 
Educación e Investigación en los Museos. El museo como centro educativo, turístico y de investigación (Santa Fe, 12, 13 y 14 de septiembre de 2008) [CD-ROM]. Santa Fe: Museo Etnográfico y Colonial "Juan de Garay"/Dirección Provincial de Patrimonio y Museos de la Provincia de Santa Fe.

Falcón, Ricardo. 1987. “Izquierdas, régimen político, cuestión étnica y cuestión nacional en Argentina (1890-1912). Anuario de la Escuela de Historia 12: 365-389.

Falcón, Ricardo. 2005. La Barcelona argentina. Migrantes, obreros y militantes en Rosario 1870-1912. Rosario: Ediciones Laborde.

Falcón, Ricardo; Alicia Megías, Beatriz Morales y Agustina Prieto. 1993. “Elites y sectores populares en un período de transición (Rosario 1870-1900)”. In Historia del sur santafesino. La sociedad transformada (1850-1930). comp. A. Ascolani. 79-120. Rosario: Editorial Platino.

Fernández, Sandra y Marisa Armida. 2000. “Una ciudad en transición y crisis (1930-1943)”. In Rosario en la Historia (de 1930 a nuestros días). Coord. Alberto J. Pla. 23-151. Tomo I. Rosario: UNR Editora.

Gutiérrez, Leandro H. y Luis Alberto Romero. 2007 [1989] “Sociedades barriales y bibliotecas populares”. In Sectores populares, cultura y política. Buenos Aires en la Entreguerra. comps. L. Gutiérrez y L. A. Romero. 71-107. Buenos Aires: Siglo XXI Editores.

Gutiérrez, Leandro H. y Luis Alberto Romero. 2007 [1991] "Los sectores populares y el movimiento obrero: un balance historiográfico". In Sectores populares, cultura y política. Buenos Aires en la Entreguerra. comps. L. Gutiérrez y L. A. Romero. 197-214. Buenos Aires: Siglo XXI Editores.

Gutiérrez Usillos, Andrés. 2010. "Reflexiones en torno a la Nueva Museología y su aplicación en los museos". In Actas de los XX Cursos Monográficos sobre el Patrimonio Histórico, coord. J. M. Iglesias Gil. 385-402. Ayuntamiento de Reinosa: Universidad de Cantabria, Servicio de Publicaciones.

Guy, Donna. 1988. “Refinería Argentina, 1888-1930: límites de la tecnología azucarera en una economía periférica". Desarrollo Económico. Revista de Ciencias Sociales 28 (111):353-373.

Hernández Hernández, Francisca. 2003. "Origen y perspectivas de la nueva museología”. RdM. Revista de Museología 26:67-91.

Lanciotti, Norma Silvia. 1999. "Mercado inmobiliario en Rosario. Racionalidad empresarial y configuración del espacio urbano (1880-1895)". Cuartas Jornadas "Investigaciones en la Facultad". Rosario: Facultad de Ciencias Económicas y Estadísticas, Universidad Nacional de Rosario. http:// www.fcecon.unr.edu.ar/investigacion/jornadas/archivos/Lanciotti.pdf

Lanciotti, Norma S. 2009. De rentistas a empresarios. Inversión inmobiliaria y urbanización en la pampa argentina. Rosario, 1880-1914. Santa Fe: Ediciones de la Universidad Nacional del Litoral.

Mencia, Marcela. 1991. "Refinería Argentina. Una industria moderna en el tránsito del nuevo siglo. 1889-1914”. Seminario II, Escuela de Historia, Facultad de Humanidades y Artes, Universidad Nacional de Rosario.

Morales, Luis Gerardo. 1995. "Los espejos transfigurados de Oaxaca”. Boletín Archivo General de la Nación 4: 13-43.

Morales Moreno, Luis Gerardo. 2000. "La nueva museología mexicana”. RdM. Revista de Museología 20:35-39.

Nicoletti, María José. 1998. "Entre el baile popular y el match de ajedrez. Los espacios de sociabilidad urbana de los años treinta. El caso de la Biblioteca Popular "Homero" de Barrio Refinería. Rosario, 1936-1939". Seminario Regional, Escuela de Historia, Facultad de Humanidades y Artes, Universidad Nacional de Rosario. 
Prieto, Agustina. 1991. "El obrero en la mira. Una aproximación a la cuestión de la identidad de los trabajadores en la Argentina del novecientos a partir de un estudio de caso". Estudios Sociales 1:107-124.

Prieto, Agustina. 1989-1990. "Condiciones de vida en el barrio Refinería de Rosario. La vivienda de los trabajadores, 1890-1914”. Anuario de la Escuela de Historia (UNR) 14.

Roigé i Ventura, Xavier. 2010. “Después de la Nueva Museología. Patrimonio, comunidad y museos locales en el contexto actual". In Actas de los XX Cursos Monográficos sobre el Patrimonio Histórico, coord. J. M. Iglesias Gil. 285-304. Ayuntamiento de Reinosa: Universidad de Cantabria, Servicio de Publicaciones.

Roldán, Diego P. 2006. La sociedad en movimiento. Expresiones culturales, sociales y deportivas (siglo XX) . Tomo X. Nueva Historia de Santa Fe. Rosario: Prohistoria Ediciones/La Capital.

Roldán, Diego P. 2008. “La formación de los sectores populares urbanos en la historiografía argentina. Una mirada sobre el núcleo”. Signos Históricos 20: 194-232.

Roldán, Diego P. 2010. "Políticas municipales y estrategias sociales. Segregación urbana, identidades, vecinalismo y politización. Rosario durante la entreguerra". In Instituciones, conflictos e identidades. De lo "nacional" a lo local. dir. M. Bonaudo. 61-93. Rosario: Prohistoria Ediciones.

Romero, Luis Alberto. 2007 [1989]. "Los sectores populares urbanos como sujetos históricos”. In Sectores populares, cultura y política. Buenos Aires en la Entreguerra. comps. L. Gutiérrez y L. A. Romero. 25-46. Buenos Aires: Siglo XXI Editores.

Simonetta, Leonardo C. y Horacio Miguel Hernán Zapata. 2010. Alta cultura, distinción pública y memorias burguesas en el prisma de la modernidad. Repensando la relación entre coleccionismo y museos en un espacio local. Rosario, primera mitad del siglo XX. In: Recordando a Walter Benjamin "Justicia, Historia y Verdad. Escrituras de la Memoria" Actas del III Seminario Internacional Políticas de la Memoria (Buenos Aires, 28, 29 y 30 de octubre de 2010) [CD-ROM]. Buenos Aires: Centro Cultural de la Memoria Haroldo Conti.

Simonetta, Leonardo C. y Horacio Miguel Hernán Zapata. 2011. “Objetos que portan historias. Actores, memorias y configuraciones identitarias en el Museo Itinerante del Barrio de la Refinería y el Museo de la Ciudad. Rosario (Argentina), 1980-2006”. In Dimensiones de la memoria histórica en un mundo globalizado. comp. J. A. Bresciano. En prensa. Montevideo: Ediciones Cruz del Sur.

Videla, Oscar y Sandra Fernández. 2000. “La evolución económica rosarina durante el desarrollo agroexportador". In Historia de Rosario. dirs. R. Falcón y M. Stanley. 55-109. Tomo I. Rosario: Homo Sapiens.

Zapata, Horacio Miguel Hernán y Leonardo C. Simonetta. 2011. "Las configuraciones de sentido en el Museo Histórico Provincial de Rosario a principios del siglo XX: memorias visibilizadas, actores negados y pasados en pugna". Temas de Historia Argentina y Americana 18:213-251.

Zapata, Horacio Miguel Hernán y Leonardo C. Simonetta. 2012. "Dos formas de recordar, una forma de valorar. Las experiencias del Museo Histórico Provincial 'Dr. Julio Marc' y del Museo Municipal de Arte Decorativo ‘Firma y Odilo Estévez' de la ciudad de Rosario (Argentina)”. In La memoria histórica y sus configuraciones temáticas. Una aproximación interdisciplinaria. comp. J. A. Bresciano. En prensa. Santiago de Compostela: Edicións Lóstrego.

Zapata, Horacio Miguel Hernán, Leonardo C. Simonetta y Misael Esquivel. 2010. "De las fruiciones privadas a las políticas públicas: colecciones, exhibiciones y museos en la configuración de la burguesía. Rosario, primera mitad del siglo XX. Recapitulando una experiencia investigativa". In Vivir en la ciudad. Tendencias estructurales y procesos emergentes. comps. E. Achilli et al. 447-461. 
Tomo II. Centro de Estudios Antropológicos en Contextos Urbanos, Universidad Nacional de Rosario/Laborde Libros Editor, Rosario.

Zapata, Horacio Miguel Hernán; Leonardo C. Simonetta y María Liz Mansilla. 2011. "Relatando historias desde abajo. El Museo de la Ciudad como lugar de Memoria: identidades sociales, espacio urbano y vida cotidiana (Rosario, Argentina, 1981-2010)". Museología e Patrimônio 4 (1):85-116. http://revistamuseologiaepatrimonio.mast.br/index.php/ppgpmus/article/ view/139/152

Zapata, Horacio Miguel Hernán; Leonardo C. Simonetta y María Liz Mansilla. 2012. "La fundación del Museo Histórico Provincial 'Dr. Julio Marc': Patrimonio, identidades y representaciones del pasado (Rosario, 1912-1950)”. Anuario de Arqueología 4 (1): 121-135.

\section{ANEXOS}

\section{Entrevista y Materiales}

Fernetti, Gustavo. 2010. Entrevista concedida por el director del Museo el 15 de marzo, en el Museo Itinerante del Barrio Refinería.

MIBR. 2006. “Curriculum del Museo”. Boletín Electrónico del Museo Itinerante del Barrio de la Refinería. http://museorefineria.blogspot.com/2006_07_01_archive.html (consultado en marzo 30, 2012).

MIBR. 2007. "Los historiadores barriales”. Blog del Museo Itinerante del Barrio de la Refinería. http://museorefineria.blogspot.com/2007_07_01_archive.html (consultado en marzo 30, 2012).

MIBR. 2008a. "Hacia otro uso del museo". Boletín Electrónico del Museo Itinerante del Barrio de la Refinería. http://museorefineria.blogspot.com/2008_08_01_archive.html (consultado en marzo 30, 2012).

MIBR. 2008b. "Una nueva mirada”. Boletín Electrónico del Museo Itinerante del Barrio de la Refinería. http://museorefineria.blogspot.com/2008_08_01_archive.html (consultado en marzo 30, 2012).

MIBR. 2008c. "Ciclo permanente de encuentros de historiadores barriales". Blog del Museo Itinerante del Barrio de la Refinería. http:// museorefineria.blogspot.com/2008_03_01_archive.html (consultado en marzo 30, 2012).

MIBR. 2008d. “Jornadas de Historiadores y Cronistas Barriales”. Blog del Museo Itinerante del Barrio de la Refinería. http://museorefineria.blogspot.com/2008_07_01_archive.html (consultado en marzo 30, 2012).

MIBR. 2009. “Encuentro 'Los viejos bares de Rosario"”. Blog del Museo Itinerante del Barrio de la Refinería. http://museorefineria.blogspot.com/2009_08_01_archive.html (consultado en marzo 30, 2012).

\section{NOTAS}

1. A los fines de especificar el cuadro explicativo de este trabajo, señalamos que entenderemos por sectores populares, como un modo de ensayar una aproximación conceptual provisoria, a 
aquel actor social cuya presencia está delimitada en un sentido relacional respecto a la clase dominante local desde fines del siglo XIX. Su posición subordinada respecto a ésta clase se encuentra en el acceso desigual a los recursos económicos, a los ámbitos de decisión política y a las arenas de participación pública. Si bien se halla conformado por componentes de distinto origen sociocultural (criollos, indígenas, negros, inmigrantes, mestizos, obreros), las experiencias de explotación laboral, las políticas disciplinamiento y control gubernamental, las estrategias de segregación espacial y social; las expresiones artísticas, culturales y deportivas a partir de los diferentes usos del tiempo libre; y los fenómenos de resistencia y contestación frente al sector dominante (tanto aquellos de índole directa, o aquellos de carácter subrepticio), fueron algunos de los factores históricos que permitieron que tales actores se construyeran como clases sociales en el entramado relacional de la ciudad de Rosario y su espacio regional. Este proceso permitirá que se elabore una percepción propia de las relaciones sociales tanto en el ámbito como en el mundo del imaginario, es decir, modalidades de sociabilidad, marcos de referencia indispensables para el accionar cotidiano y situaciones excepcionales de interacción), subjetividades y configuraciones identitarias complejas, múltiples y contradictorias. Acerca del debate sobre la forma de nominar a estos grupos sociales en la historiografía argentina, cf. Romero (2007 [1989]); Pla (1989-1990); Gutiérrez y Romero (2007 [1991]) y Roldán (2008).

\section{RESÚMENES}

En Argentina, la adopción de las premisas de la "nueva museología" a partir de la década de 1980 indujo a que muchos de los museos existentes en el país generaran nuevas estrategias de organización y gestión y renovaran sus formas de comunicación e interacción con el público, transformándose así en instituciones capaces de traducir la pluralidad de características, asimetrías y fracturas políticas, sociales y culturales de la sociedad. Tales cuestiones están siendo revisadas por nuevas investigaciones que obligan a indagar casos concretos, para luego reposicionar su especificidad dentro de un marco general. El artículo examina la forma en que se tradujeron tales discursos y políticas museológicas en la ciudad de Rosario (Santa Fe) a partir del análisis de las condiciones bajo las cuales el Museo Itinerante del Barrio de la Refinería configura una propuesta específica de exhibición y lectura del patrimonio.

In Argentina, the adoption of the premises of "new museology" since the 1980s meant that many of the existing museums in the country generated new organization and management strategies and renewed their forms of communication and interaction with the public, becoming institutions able to use the plurality of political, social and cultural characteristics, the asymmetries and fractures of society. Such questions are being reviewed by new research that forces us to study concrete cases and to relocate its cultural specificity into a framework of general analysis. This paper examines the way in which such museological discourse and policies were used in the city of Rosario (located in the province of Santa Fe), analyzing the conditions under which the "Museo Itinerante del Barrio de la Refinería" forms a specific exhibition proposal and reading of heritage. 


\section{ÍNDICE}

Keywords: new museology, popular memory, neighbor identity, local museum, Rosario (Argentina)

Palabras claves: nueva museología, memoria popular, identidad vecinal, museo local, Rosario (Argentina)

\section{AUTORES}

\section{HORACIO MIGUEL HERNÁN ZAPATA}

Horacio Miguel Hernán Zapata es profesor y licenciado en Historia por la Universidad Nacional de Rosario (Argentina), donde se desempeña como docente de la cátedra "Historia Argentina II" y como miembro del Centro Interdisciplinario de Estudios Sociales. Participa de proyectos de investigación de radicados en la UNR, en la Universidad de Buenos Aires, en la Universidade de São Paulo (Brasil) y en la Diakonhjemmet University College (Noruega). Atualmente reviste como becario doctoral del Consejo Nacional de Investigaciones Científicas y Técnicas en el nodo Centro de Estudios Sociales Regionales) de la Unidad Ejecutora en Red en Investigaciones SocioHistóricas Regionales. Ha participado de numerosos congresos, seminarios y jornadas como así también editado varios capítulos de libros y artículos de revistas nacionales y extranjeras. En este momento investiga las relaciones sociales y étnicas en los espacios de frontera (Chaco, Pampa y Patagonia) y los vínculos entablados entre las poblaciones indígenas y el Estado Argentino durante el siglo XIX. horazapatajotinsky@hotmail.com CESOR-ISHiR-CONICET/Escuela de Historia-CIESo-UNR/Sección Etnohistoria-ICA-UBA (Argentina).

\section{LEONARDO C. SIMONETTA}

Leonardo C. Simonetta es profesor en Historia por la Universidad Nacional de Rosario, donde se desempeña como docente de la cátedra "Historia Argentina II" y como miembro del Centro Interdisciplinario de Estudios Sociales. Participa de proyectos de investigación de radicados en la UNR y en la Diakonhjemmet University College (Noruega). Atualmente trabaja en el Centro Documental "Ruben Naranjo" del Museo de la Memoria y reviste como becario del Programa Estímulo a las Vocaciones Científicas del Consejo Interuniversitario Nacional en el nodo CESOR (Centro de Estudios Sociales Regionales) de la Unidad Ejecutora en Red en Investigaciones SocioHistóricas Regionales del CONICET. En este momento investiga la participación política, formas de sociabilidad y configuración de identidades de inmigrantes europeos en el sur de Santa Fe durante la segunda mitad del siglo XIX. leosimonetta@hotmail.com CESOR-ISHiR-CIN/Escuela de Historia-CIESo-UNR/Museo de la Memoria-Municipalidad de Rosario (Argentina).

\section{MARÍA LIZ MANSILLA}

María Liz Mansilla es profesora en Historia por la Universidad Nacional de Rosario (Argentina), donde se desempeña como docente de la cátedra "Historia Argentina II" y como miembro del Centro Interdisciplinario de Estudios Sociales. Participa de proyectos de investigación de radicados en la UNR y en Programa de Voluntariado Universitario auspiciado por la Secretaría de Políticas Universitarias del Ministerio de Educación de la Nación. Ha sido guía en el Museo 
Municipal de Arte Decorativo Firma y Odilo Estévez y en el Museo de la Ciudad de Rosario y Conductora-Tallerista del Programa "Más y mejor Empleo" financiado por el Ministerio de Trabajo de la Nación. En este momento investiga problemáticas que vinculan a la historia cultural de las revistas y proyectos editoriales del sur de Santa Fe en las primeras décadas del siglo XX. marializmansilla@hotmail.com

Filiación académica: Escuela de Historia-CIESo-UNR (Argentina). 